УДК 349.2

\title{
СТАНОВЛЕНИЕ ФАБРИЧНОГО ЗАКОНОДАТЕЛЬСТВА В СФЕРЕ РАЗРЕШЕНИЯ КОЛЛЕКТИВНЫХ ТРУДОВЫХ СПОРОВ
}

Исторический аспект изучения проблем урегулирования коллективных трудовых споров в России заслуживает более пристального внимания, в том числе сквозь призму современных проблем правового регулирования отношений в сфере труда. Исторический анализ правовых норм нацеливает законодателя на разработку эффективного механизма адекватного отражения закономерностей развития трудовых отношений. Выявление конкретных объективных и субъективных условий возникновения коллективных трудовых споров ориентирует на устранение их негативных последствий и является актуальным, по сей день.

Статья посвящена правовому анализу дореволюционного периода становления в Ставропольской губернии механизмов мирного разрешения коллективных трудовых конфликтов. В ней рассмотрены на фоне отсутствия правовой регламентации российского фабрич- ного законодательства, применяемые в практике меры по урегулированию разногласий между работодателями и работниками по материалам государственного краевого архива Ставропольского края. Автором впервые анализируется порядок разрешения коллективных трудовых конфликтов, органами, созданными в губернии на принципе равноправия участия спорящих сторон, показа роль рабочего движения, профессиональных союзов за свои трудовые права. Автором акцентируется значение заключения коллективных трудовых договоров как фундамента локального регулирования коллективных трудовых споров.

Ключевые слова: коллективные трудовые конфликты, рабочие, работодатели, трудовые права, стачечное движение, забастовка, требования рабочих, профессиональные союзы, органы по разрешению трудовых конфликтов, коллективных договор.

T. Vysheslavova

\section{FORMATION OF FACTORY LEGISLATION IN THE FIELD OF COLLECTIVE LABOR DISPUTES RESOLUTION}

The historical aspect of the study of the problems of settlement of collective labor disputes in Russia deserves closer attention, including through the prism of modern problems of legal regulation of relations in the field of labor. Historical analysis of legal norms focuses the legislator on the development of an effective mechanism of adequate reflection of the laws of labor relations. Identification of specific objective and subjective conditions of collective labor disputes focuses on the elimination of their negative consequences and is relevant to this day.

The article is devoted to the legal analysis of the pre-revolutionary period of formation of mechanisms of peaceful settlement of collective labor conflicts in Stavropol province. Against the background of the lack of legal regulation of the

Исторический опыт правового регулирования коллективных конфлликтов в сфрере трудовых отношений актуален и в настоящее время. Никуда не делась полярность интересов труда и капитала, различная оценка общественных ценностей участниками коллективных трудовых споров. Коллективным трудовым спорам присуще разнообразие объектов противоборства, наличие пробелов трудового законодательства, проблемы в экономике и социальной политике государства.

Все правовые явления в трудовом праве связаны с принципом историзма юридической науки,
Russian factory legislation it examinesthe applied in practice measures to resolve disputes between employers and employees on the materials of the state regional archive of the Stavropol territory. The author analyzes for the first time the order of collective labor conflicts resolution, the bodies established in the province on the principle of equal participation of the disputing parties, the role of the labor movement, trade unions for their labor rights. The author emphasizes the importance of collective labor agreements as the foundation of local regulation of collective labor disputes.

Key words: collective labor disputes, workers, employers, labor rights, strike movement, strike, workers' demands, trade unions, labor dispute resolution authorities collective agreements.

который нацеливает законодателя на обоснование новаций в правовом регулировании разрешения коллективных трудовых споров.

В Ставрополье исторически складывались предпосылки специфического воздействия на общественные отношения в сфере наемного труда. Это явление объясняется особым географическим положением края, исключительным набором трудовых и экономических ресурсов.

В конце 70-Х гг. XIX в. в Ставропольской губернии развиваются трудовые капиталистические отношения. Возникают противоречия между ра- 
ботодателями и наемными рабочими, требующие законодательного урегулирования. В это время уже в России действуют законодательные акты регулирующие взаимоотношения участников труда на фабриках, заводах, мануфактурах. Они издавались в форме положений, указов, инструкций, докладов, правил, записок, наказов, фабричных уставов и т.д. [16, с. 167]

Мелкие промышленные заведения в губернии действовали с 1861 г. по переработке сельскохозяйственного сырья, свинцовой и цинковой руды использованию кислых и железных источников $[14$, c. 209].

Рабочая сила пополнялась из рядов крестьян, вследствие реформы 1861 г., которая концентрировалась в Ставрополе, крупных городах губернии и по Владикавказской железной дороге Развивался торговый капитал, разрабатывались минеральные источники. Экономика губернии строилась на промышленном развитии железнодорожного транспорта, где Ростово-Владикавказская железная дорога была одной из самой доходной того времени. Железная дорога явилась ситемообразующим предприятием, на базе которого учреждались мастерские, депо, небольшие заводы по металлообработке и добыче нефти. Тут особо можно выделить Минераловодские мастерские. Железной дороге принадлежал Новороссийский порт, как промышленное предприятие по продаже ставропольской пшеницы [11, с. 158].

Росли противоречия между промышленниками и рабочими, не прекращались крестьянские волнения, говорившие об острой проблеме земельного вопроса в губернии. Тяжелые условия труда, быстрый рост промышленного производства были катализаторами коллективных конфликтов Назревали проблемы во взаимных отношениях рабочих и работодателей

Однако открытые выступления рабочего класса против работодателей на Ставрополье начинаются в 1905 г. как отклик общероссийского движения пролетариата за свои трудовые права. Так рабочий день на промышленных предприятиях составлял 12-16 часов, контроль за техникой безопасности отсутствовал, усиливалась промышленная эксплуатация крестьян.

По сведениям губернского архива того времени, наемные рабочие Медвежинского уезда отказывались от условий заключения договора за половину урожая, а рабочие Прасковейских мукомольных мельниц работали в очень тяжелых условиях [2, л. 115].

С целью урегулирования конфликтов в сфере наемного труда в губернии действовали судебные уставы, предусматривающие их разрешение в мировом суде, при урегулировании споров применялись нормы Городового положения 1870 г

В 1882 г. для разрешения коллективных трудовых конфрликтов была учреждена Камера старшего фрабричного инженера Черноморской губернии действующая и на Ставрополье, руководствующаяся нормами Устава о промышленном труде где разрешались споры, связанные с несчастными случаями, зафиксированными на мельницах губернии [6, л. 1-5].
Массовость рабочих выступлений за свои трудовые права, отмеченные по материалам Ставропольского краевого архива, начались с января 1905 г. забастовкой на чугунолитейном заводе Руднева и Шмидта, где в результате забастовки работодатель сократил рабочий день до 10 часов [3, л. 17]. Летом того же года возник конфликт рабочих на Минераловодском участке Владикавказской железной дороги с работодателем. Рабочие выдвигали требования повышения заработной платы, запрещения штрафов, установления 8-ми часового рабочего дня, введения страхования, надлежащего контроля за охраной труда. Наряду с этими экономическими требованиями предъявлялись и политические - свободы собраний, митингов, союзов рабочих. Рабочие предупреждали администрацию об отказе применения увольнений или арестов рабочих в ходе стачки, в противном случае они объявят забастовку, где «всякие работы, движение по Минераловодскому узлу тяги незамедлительно будут приостановлены» [12].

Администрация отказала требованиям рабочих, кроме того на подмогу были вызваны войска. Защищая свои трудовые права, рабочие объявили забастовку 11 июля 1905 г. Эту забастовку поддержали и другие рабочие паровозных бригад, прибывших на станцию Минеральные Воды, отказавшихся от ведения железнодорожных составов. Этот пример послужил началом всеобщей стачке на Владикавказской железной дороге, к которой примкнули многие станции.

В ответ на игнорирование требований администрации возобновить работу и восстановить железнодорожное движение, к забастовщикам решено было применить локаут. Работодатель распорядился об увольнении тех рабочих, которые не выйдут на работу 13 июля 1905 г. Однако и эта мера не прекратила стачку, руководимую стачечным бюро [11, с. 192].

Такие решительные коллективные действия рабочих заставили администрацию железной дороги вступить в переговоры с рабочими и удовлетворить их отдельные экономические требования. Правда, из предъявленных рабочими 34 требований было удовлетворено только три.

Во-первых, администрация обязывалась снова принять на работу уволенных рабочих без потери их прав. Во-вторых, отказаться от усмотрения начальника депо по приему на работу работников - участников стачки. В-третьих, время стачки оформлялось для работников днями отпуска. К сожалению требование рабочих о сохранении заработной платы в период стачки было решительно отклонено администрацией [15]. 30 июля 1905 г. стачка была прекращена. Однако материалы краевого архива свидетельствуют о многочисленных забастовках в губернии на мелких промышленных предприятиях.

Все это говорит о том, что при отсутствии правового регулирования права на забастовку в российском законодательстве, представители работодателей предпочли мирный выход из забастовок и стачек, не применяя ст. 1358 и 1381 действующего Уложения о наказаниях, что потом 
стало фундаментом урегулирования коллективных трудовых споров.

Переговоры велись на паритетной основе из представителей работодателя и рабочих, где их интересы представляло выбранное стачечное бюро. Таким образом, разрешение разногласий работодателя и наемных работников приобретает определенный механизм, где формируется посредничество сторон, примирительные процедуры, при полном отсутствии законодательного урегулирования.

Стачечное движение в губернии набирало силу и уже 8 ноября 1905 г. рабочие чугунолитейного завода Руднева и Шмидта опять бастовали, требуя улучшения условий труда и социального обеспечения. Забастовка продлилась 5 дней, рабочие не добились ей результатов, но она стала примером для рабочих Пятигорска, Георгиевска, Минеральных Вод и трудового крестьянства.

Дпя наблюдения за порядком и недопущения массовых волнений в губернии создается Особая Комиссия при управлении Владикавказской железной дороги. Она издала 16 сентября 1906 г постановление запрещающее создание и действие рабочих бюро и комитетов, не разрешенных в установленном порядке, а также проведение собраний и митингов. Предписывалось во время забастовки прекращать работу потребительских лавок, уволенных работников удалять с полосы отчуждения железной дороги, а виновные, нарушающие данное положение могли подвергаться аресту на три месяца или денежному штрафу в размере до 500 рублей $[1$, л. 1-2].

Несмотря на это в 1907 г. бастовали рабочие сел Китаевского, Круглолесского, а в 1908 г. - сел Маслов-Кут, в 1912 г. - станции Курсавка. Министерство путей сообщений принимает «Правилао порядке увольнения и перемещения политически неблагонадежных железнодорожных служащих по требованию жандармской полиции» от 3 октября 1909 г., где наемные работники могли быть уволены, подвергнуты высылке как неблагонадежные. Обратный прием на работу осуществлялся с согласия полиции. Вводятся специальные циркуляры о запасных наборах специалистов для замены ими бастующих рабочих [7, л. 11].

Этими коллективными действиями рабочие добились снижения цены на хлеб, хоть и незначительного, но повышения заработной платы, усиления работы фабричного инспектора Черноморской губернии. Так данный фабричный инспектор, обращаясь к Ставропольскому губернатору, отмечал, что при наличии трудового конфликта, рабочие могут обращаться в суд, при отсутствии специального органа правительственной власти, регулирующего данные коноликты. Он обращает внимание на отсутствие у него полномочий на вмешательство во взаимоотношения между работодателями и наемными рабочими и ходатайствует о необходимости скорейшего ведения на Ставрополье ст. 48-60 и 125-156 Устава о Промышленности, в качестве регламентации действий администраций при нарушении промышленного порядка $[4$, л. 2].
Для защиты экономических интересов рабочих в 1905 г. на Ставрополье созданы были профсоюзы правительственных учреждений, а также союзы пекарей, почтовых работников и другие. Позднее были созданы профессиональные союзы железнодорожников, работников промышленных предприятий. Их деятельность регламентировалась уставами, включающими нормы о необходимости вступать в коллективные переговоры с представителями хозяев по установлению условий труда, где основное место занимали вопросы увеличения оплаты труда, снижения норм рабочего времени. Уже в уставах предписывалось при возникновении трудовых конфоликтов учреждать примирительные камеры, где представители сторон конфрликта могли урегулировать разногласия и споры. К 1917 г. в губернии действовали профессиональные союзы печатников, строителей, кожевников, металлистов и другие. На их основе в центре губернии в г. Ставрополе начало действовать Центральное Бюро профсоюзов, как организующий и руководящий орган. Однако большого влияния на рабочее движение по защите интересов рабочих оно не сыграло, в силу того, что в его руководстве оказались меньшевики и эсеры, проводившие туманную политику по отношению к интересам рабочих, не уделяя внимания вопросам о разрешении трудовых конфликтов [8, л. 1-2].

Деятельность данного Бюро также регламентировалась уставом, в котором предписывалась деятельность по объединению всех профсоюзов губернии, определялись цели и задачи, но не было ничего сказано по созданию механизмов по урегулированию трудовых конфрликтов, слабы были начинания по действенной защите экономических интересов рабочих. Работа Бюро сосредотачивались в крупных предприятиях, мелкие же предприятия были мало охвачены профсоюзным движением.

Однако в ответ на рост стачечного движения, как на крупных предприятиях, так и мелких производствах, при губбюро был создан тарифно-стачечный отдел. В его компетенцию входили вопросы экономический борьбы, повышение заработной платы и разрешение споров в данной сфере. Кроме того, Бюро сформировало конфликтную комиссию, где разбирались разногласия хозяев и рабочих по условиям труда. Примером такого рассмотрения комиссией явились споры между работодателем и профсоюзом «Игла», а также завода «Адольфа Шмидта». Интересы рабочих в данных консрликтах представляли стачечные комитеты, которые объявляли забастовки и выдвигали требования [13, с. 342].

С целью разрешения коллективных трудовых споров в 1917 году в губернии создается Ставропольская городская примирительная камера, где рассматривались разногласия между работниками и предпринимателями с непосредственным участием, как конфликтной комиссии, так и представителей Бюро.

Примером камерного разбирательство может служить требования Союза работников печатно- 
го дела о повышении заработной платы в целом на 25 рублей всем работникам. В коллективных переговорах участвовали представители конфликтной комиссии и представители работников и хозяина. Переговоры не принесли ощутимых результатов и в июле 1917 г. работники печати объявили забастовку, которая была поддержана и Бюро. В это время уполномоченный газеты "Северокавказское слово» обращался в Бюро с просьбой отложить забастовку или задержать до рассмотрения разногласий в примирительной камере, ссылаясь, что нельзя оставить население без газет и телеграмм в то непростое для страны время $[9$, л. 6,17$]$

Достаточно активно работал тарифно-стачечный отдел Ставропольского губбюро по разрешению коллективных трудовых споров связанных с улучшением условий оплаты труда рабочих. Значимость работы этого органа примирения была очевидна, так как им в значительной степени гасились возмущения рабочих мелких предприятий губернии. Так тарифно-стачечным отделом урегулированы разногласия рабочих и предпринимателем Бандерсоном в пищевой отрасли, где забастовка была предотвращена условиями работы установленными Продовольственным комитетом губернии.

Таким образом, примирительная комиссия, тарифно-стачечный отдел, конфликтная комиссия и само губбюро являлись действенными органами по разрешению трудовых конфоликтов, особенно при рассмотрении требований рабочих и мирном урегулировании взаимоотношений между ними и работодателями. Тем более, что требования рабочих не всегда признавались обоснованными и тем самым предотвращались неорганизованные и стихийные забастовки и другие меры протеста рабочих. Бюро как основной орган по урегулированию конфликтов уже корректировал рабочее движение в губернии, разрабатывая объективные требования к работодателям и принимал предупредительные меры для предотвращения забастовок и возникновению коллективных трудовых споров. В общественной жизни края значительное место занимали вопросы профилактики возникновения трудовых конфликтов на основе мирного их урегулирования и активного участия в них как самих рабочих, так и предпринимателей.

Концентрация наемной рабочей силы на Ставрополье в то время была значительной, так по данным Ставропольского краевого архива, в разных отраслях хозяйства трудилось 40 тысяч рабочих из которых 7,5 тысяч человек работали на заводах и фабриках. В составе Ставропольского губернского бюро профсоюзов насчитывалось 11 союзов, объединяемых 3, 5 тысячи рабочих.

Основными требованиями рабочих были вопросы улучшения охраны труда, повышения заработной платы, условия об отказе работодателей увольнения рабочих участвовавших в забастовках, обратного приема на работу таких рабочих. Однако рабочие испытывали на себе последствия участия в забастовках и работодатели, часто игнорировали свои обещания о неприменении такой меры как увольнение рабочих. Так, последствием забастовки рабочих на мельнице братьев Милосердовых в г. Ставрополе явилось увольнение крупчатника данной мельницы, несмотря на обещание промышленников не отвечать репрессиями на последствия забастовки. Бюро отреагировало на такие действия промышленников, им предлагалось рассмотреть последствия забастовки и свои обещания и принять незамедлительно соответствующие меры [10, л. 3-4].

Таким образом, при отсутствии правового регулирования в российском законодательстве норм регламентирующих порядок разрешения трудовых конфликтов, нарушались в одностороннем порядке взятые на себя обязательства при улаживании забастовок. Практика говорила об отсутствии механизмов ответственности предпринимателей при достижении соглашений по мирному разрешению споров. В свою же очередь профсоюзы рабочих не могли оказать на них должного влияния, при нарушении работодателями своих обещаний, принятых в добровольном порядке при проведении коллективных переговоров с рабочими.

В это же время началась практика заключения коллективных договоров на предприятиях и организациях губернии, что регламентировало взаимоотношения между рабочими и работодателями. В них уже появились такие нормы как запрещение предпринимателей пререкания с рабочими, при возникновении разногласий заявлять в секретариат Союза, наложение штрафа на работодателя, принявшего на работу работника без специальной карточки Союза и другие. Нормы по мирному урегулированию трудовых конфликтов включались в действующие правила внутреннего распорядка, где запрещалось рабочим собираться в «кучи», отсутствовать на работе без уважительных причин, а значив и в случае забастовки. Тут же действовали табели о взысканиях, так за неявку на рабочее место с рабочего удерживалась дневная заработная плата [5, л. 1-6] Устанавливалось локальное регулирование, добровольное взятие обязательств сторонами спора, пробелы законодательства, устраняясь ведением коллективных переговоров.

Таким образом, в дореволюционный период в Ставропольской губернии создались благоприятные предпосылки мирного разрешения коллективных трудовых споров. Данный период характеризуется ущемлением трудовых прав рабочих, тяжелыми условиями их труда, что способствовало наличию разногласий между работниками и работодателями, что нередко приводило к стачкам и забастовкам.

В губернии плохо осуществлялся надзор за неукоснительным выполнением действующих правительственных циркуляров и Устава о промышленности, что влияло на рабочее движение в губернии и жестокую эксплуатацию наемных работников. Однако силами профессиональных союзов и промышленников в губернии были созданы органы по урегулированию коллективных трудовых споров, что, несомненно, указывает 
на то, что именно в этот период закладываются основные механизмы по разрешению трудовых конфликтов на мирной основе. Предприниматели губернии достаточно рано признали силу профсоюзов, созданных примирительных органов по разрешению конфликтов, коллективных переговоров, где представители рабочих выступали как равноправная сторона. Заключение коллективных трудовых договоров, регламентация ра- бочей жизни в правилах внутреннего распорядка создало предпосылки к локальному регулированию взаимоотношений труда и капитала. Мирное разрешение трудовых конфоликтов на принципах паритетности способствовало разработке на локальном уровне процедур разрешения коллективных трудовых споров и служило профилактирующим механизмом для их предотвращения.

1. ГАСК. Ф. 101. ОП. 5. Д. 383

\section{Литература}

2. ГАСК. Ф. 101. ОП. 5. Д. 414.

3. ГАСК. Ф. 101. ОП. 5. Д. 552.

4. ГАСК. Ф. 133. ОП. 1. Д. 95.

5. ГАСК. Ф.133. Оп. 1. Д. 115.

6. ГАСК. Ф. 133. Оп. 1. Д. 170

7. ГАСК. Ф. 1008. Оп. 1. Д.60

8. ГАСК. Ф. 2430 . ОП. 1. Историческая справка.

9. ГАСК. Ф. 2430. Оп. 1. Д. 6.

10. ГАСК. Ф. 2430 . Оп. 1. Д. 14

11. История Ставропольского края от древних времен до 1917 г. / под ред. Невской В. П. Ставрополь: СКИПКРО 1996. $196 \mathrm{c}$.

12. Кавказские Минеральные Воды. 1905. 14 июля

13. Наш край 1777-1917. Документы и материалы. Ставрополь: Ставропольское книжное издательство, 1977. 424 с.

14. Очерки истории Ставропольского края. Т.1. С древних времен до 1917 г. Ставрополь: Ставропольское книжное издательство, 1984. 383 с.

15. Политический листок. 1905. 28 июля.

16. Рыбаков Ю. Я. Промышленное законодательство России первой половины XIX века. М.: Наука, 1986. 214 c.

\section{References}

1. State archive of Stavropol territory (GASK). F. 101. Inv. 5. D. 383. (In Russian)

2. GASK. F. 101. Inv. 5. D. 414. (In Russian)

3. GASK. F. 101. Inv. 5. D. 552. (In Russian)

4. GASK. F. 133. Inv. 1. D. 95. (In Russian)

5. GASK. F. 133. Inv. 1. D. 115. (In Russian)

6. GASK. F. 133. Inv. 1. D. 170. (In Russian)

7. GASK. F. 1008. Inv. 1. D. 60. (In Russian)

8. GASK. F. 2430. Inv. 1. Historical information. (In Russian)

9. GASK. F. 2430. Inv. 1. D. 6. (In Russian)

10. GASK. F. 2430. Inv. 1. D. 14. (In Russian)

11. Istorija Stavropol'skogo kraja ot drevnih vremen do $1917 \mathrm{~g}$. (History of Stavropol region from ancient times to 1917) I ed. Nevskaya V. P. Stavropol: SKIPCRO publ., 1996. 196 p. (In Russian)

12. Kavkazskie Mineral'nye Vody. 1905. July 14. (In Russian)

13. Nash kraj 1777-1917. Dokumenty imaterialy (Our region 1777-1917. Documents and materials). Stavropol: Stavropol book publishing house, 1977. 424 p. (In Russian)

14. Ocherkiistorii Stavropol'skogo kraja. T. 1. S drevnih vremen do $1917 \mathrm{~g}$. (Essays on the history of the Stavropol territory). Vol. 1. From ancient times to 1917). Stavropol: Stavropol book publishing house, 1984. 383 p. (In Russian)

15. Politicheskij listok. 1905. July 28. (In Russian)

16. Rybakov Yu. Ya. Promyshlennoe zakonodatel'stvo Rossii pervoj poloviny XIX veka (Industrial legislation of Russia in the first half of the XIX century). Moscow: Nauka publ., 1986. 214 p. (In Russian)

\section{Сведения об авторе}

Вышеславова Татьяна Федоровна - кандидат юридических наук, доцент кафедры экологического, земельного и трудового права юридического института Северо-Кавказского федерального университета (Ставрополь) / vysheslavova_tf@mail.ru

\section{Information about the author}

Vysheslavova Tat'jana - PhD in Law, Accossiate Professor, Chair of Environmental, Land and Labor Law, Instute of Law, North-Caucasus Federal Institute (Stavropol) / vysheslavova_tf@mail.ru 